\title{
A Novel Mutation Causing Pseudohypoparathyroidism 1 A with Congenital Hypothyroidism and Osteoma Cutis
}

\author{
Tamar Lubell, Maria Garzon*, Kwame Anyane-Yeboa**, Bina Shah *** \\ Department of Pediatrics, New York University Medical Center, New York, USA \\ ${ }^{*}$ Department of Dermatology, Columbia University, New York, USA \\ ${ }^{* *}$ Department of Pediatrics, Columbia University, New York, USA \\ ***Department of Pediatric Endocrinology, New York University Medical Center, New York, USA
}

\begin{abstract}
Various inactivating mutations in guanine nucleotide-binding protein, alphastimulating activity polypeptide1 (GNAS1) gene have been described with poor phenotype correlation. Pseudohypoparathyroidism type 1a (PHP1a) results from an inactivating mutation in the GNAS1 gene. Hormone resistance occurs not only to parathyroid hormone (PTH), but typically also to other hormones which signal via $\mathrm{G}$ protein coupled receptors including thyroid stimulating hormone (TSH), gonadotropins, and growth hormone releasing hormone. In addition, the phenotype of Albright hereditary osteodystrophy (AHO) is observed, which may include short stature, round facies, brachydactyly, obesity, ectopic soft tissue or dermal ossification (osteoma cutis) and psychomotor retardation with variable expression.

We present a 2-year-old boy with PHP 1 A who initially presented at age 3 weeks with congenital hypothyroidism. By 17 months of age, he manifested osteoma cutis, psychomotor retardation, obesity, brachydactyly and resistance to PTH with normocalcemia and mild hyperphosphatemia.

Genetic analysis revealed a novel mutation in exon 13 of GNAS1 in our patient. This mutation, c.1100_1101insA, resulted in a frameshift and premature truncation of bases downstream. This mutation was also found in the mother of this patient who was also noted to have short stature, obesity, brachydactyly and non progressive osteoma cutis, but no hormone resistance.

We report a novel heterozygous mutation causing PHP1A with PTH and TSH resistance and $\mathrm{AHO}$ which has not been described previously. PHP1A is also a rare presentation of congenital hypothyroidism.

Key words: Pseudohypoparathyroidism, osteoma cutis, congenital hypothyroidism
\end{abstract}

Received: 27.06 .2009
Accepted: 05.08.2009

\section{Introduction}

Pseudohypoparathyroidism (PHP) represents a heterogeneous group of disorders characterized by end-organ unresponsiveness to PTH leading to hypocalcemia, hyperphosphatemia, and elevated PTH concentrations. PHP is divided into types $1 \mathrm{a}, 1 \mathrm{~b}, 1 \mathrm{c}$ and type 2 that differ with respect to phenotype and hormone resistance patterns. PHP type 1 is associated with a diminished urinary CAMP and phophaturic response to exogenous PTH administration (1). In addition to hormone resistance, patients with PHP type 1a also display a constellation of findings known as Albright hereditary osteodystrophy (AHO). AHO may be characterized by short stature, round facies, brachydactyly, obesity, ectopic soft tissue or dermal ossification (osteoma cutis), developmental delay and reduced Gs $\alpha$ activity (2). The features of AHO are also present in pseudopseudohypoparathyroidism (PPHP), but PPHP differs in that there is no associated hormone resistance. PHP 1b is characterized by PTH-resistance with hypocalcemia and hyperphosphatemia but without the features of AHO. Patients with PHP1c differ from PHP1a patients in that they have multiple hormone resistance but normal Gs $\alpha$ activity. Finally, patients with PHP2 have a normal cAMP response to PTH but have an impaired phosphaturic response.

We herein report a case of PHP1a presenting with congenital hypothyroidism, PHP, osteoma cutis, obesity and psychomotor retardation. These manifestations of PHP1a resulted from a novel mutation in the guanine nucleotide-binding protein, alpha-stimulating activity polypeptide 1 (GNAS1) gene.

\section{Address for Correspondence}

Bina Shah, MD, Department of Pediatrics, New York University Medical Center, 550 First Avenue, New York, NY 10016 Phone: +90 804-747-5087 Fax: +90 804-828-3256 E-mail: Bina.shah@nyumc.org

(c) Journal of Clinical Research in Pediatric Endocrinology, Published by Galenos Publishing. All rights reserved. 


\section{Case Report}

The proband was born full term via cesarean section. His birth weight was $3458 \mathrm{~g}$ and length was $50 \mathrm{~cm}$. His mother had an uncomplicated pregnancy. He was found to be jaundiced on day three of life with resolution of his hyperbilirubinemia after 24 hours of phototherapy. Neonatal thyroid function screening revealed a plasma total thyroxine of $8.6 \mathrm{ug} / \mathrm{dL}$ (normal range 10 to $20 \mathrm{ug} / \mathrm{dl}$ ) and an elevated thyroid stimulating hormone $(\mathrm{TSH}$ ) of $32 \mathrm{uU} / \mathrm{mL}$ (normal range $<20 \mathrm{uU} / \mathrm{mL}$ ) on post natal day 2, compatible with congenital hypothyroidism.

On initial examination at three weeks of age, the patient's weight was $3855 \mathrm{~g}$. Physical findings, with the exception of an umbilical hernia, were unremarkable. The anterior fontanel was open and the posterior fontanel was closed. There was no goiter. There was no hypotonia. He had normal prepubertal male genitalia with descended testes bilaterally. The patient was started on Levothyroxine 25 micrograms, at 3 weeks of age, at which time his free T4 was $1.0 \mathrm{ng} / \mathrm{dl}$ (normal range 0.8 to $2.2 \mathrm{ug} / \mathrm{dl}$ ) and his TSH was $12.8 \mathrm{uU} / \mathrm{mL}$ (normal range 0.5 to $4.5 \mathrm{uU} / \mathrm{mL}$ ). A sonogram of the neck was performed at 5 weeks of age which showed a right thyroid lobe measuring approximately $15 \times 8 \times 8 \mathrm{~mm}$ (right thyroid lobe volume of $0.5 \mathrm{cc}$ ). There was a solitary nodule in the mid aspect of the right lobe of the thyroid measuring $5.0 \times 3.0 \times 4.0 \mathrm{~mm}$. The left lobe of the thyroid measured $12 \times 7 \times 7 \mathrm{~mm}$, (left thyroid lobe volume of $0.3 \mathrm{cc}$ ) with no nodules identified. A repeat sonography at 8 months of age showed a stable appearance of the right lobe nodule.

At 17 months of age, subcutaneous ossification was noted on the left thumb. Subsequent radiologic examination of the hands showed an area of calcification at the left first metacarpalphalangeal joint as well as diffuse osteopenia, and an advanced bone age of 4 years at a chronologic age of 26 months. Serum biochemistry at 21,25 and 28 months of age revealed PTH levels of 98, 228 and $237 \mathrm{pg} / \mathrm{mL}$ respectively (normal range $15-75 \mathrm{pg} / \mathrm{ml}$ ), marginally elevated phosphate levels (6.7, 6.5 and $6.3 \mathrm{mg} / \mathrm{dL}$, normal range $4.5-5.5 \mathrm{mg} / \mathrm{dL})$ and calcium levels of $10.1,9.5$ and $9.3 \mathrm{mg} / \mathrm{dL}$ (normal range 8.3 $10.3 \mathrm{mg} / \mathrm{dl}$ ). The 25-hydroxy vitamin D level was $27 \mathrm{ng} / \mathrm{ml}$ (normal range $30-80 \mathrm{ng} / \mathrm{ml}$ ) and 1,25-dihydroxy vitamin D level was $64 \mathrm{pg} / \mathrm{ml}$ (normal range 15-75 pg/ml) at 27 months.

A review of the patient's growth data revealed that his height corresponded to $81^{\text {st }}$ centile for age ( $Z$ score 0.864$)$ at 13 months of age and to $76^{\text {th }}$ percentile ( $Z$ score 0.706$)$ at 25 months of age. His weight centiles changed from $86^{\text {th }}$ centile ( $Z$ score 1.084 ) to over $99^{\text {th }}$ centile ( $Z$ score 2.377 ) in the same period. His body mass index at 25 months of age was $20.7 \mathrm{~kg} / \mathrm{m}^{2}$ (>97th centile, Z score 2.31).

The patient showed a delayed motor and language development and he is currently receiving occupational therapy, speech therapy and special education.

The patient's mother also showed features of $\mathrm{AHO}$ including obesity, short $4^{\text {th }}$ and $5^{\text {th }}$ metacarpal bones with multiple areas of ectopic calcium deposits which were present for 21 years and were non progressive. There was no evidence of hormone resistance in the mother; her PTH was $31.5 \mathrm{pg} / \mathrm{ml}$ (normal range 10-65 pg/ml).

\section{Genetic Study Results}

Mutations in the gene encoding Gs $\alpha$ (GNAS1) were investigated by polymerase chain reaction (PCR) and DNA sequencing of exons 1 (codon 7-43) through 13. A novel mutation, c.1100_1102insA, was detected in exon 13 which resulted in a frameshift and premature termination, 10 amino acids downstream. This mutation was also identified in the patient's mother. This alteration is not considered as a polymorphism.

\section{Discussion}

PHP has been linked to mutations in the gene encoding the alpha subunit of the stimulatory G protein (GNAS1), which maps to 20q13.2. The inheritance pattern appears to be autosomal dominant and displays variable penetrance. The GNAS1 locus is very complex and gives rise to Gs $\alpha$ and several other splice variants $(3,4)$. Estimates of the proportion of AHO caused by GNAS1 mutations range from 60 to $90 \%$. These mutations have been described throughout the 13 exon gene. Approximately 35 to $50 \%$ of reported mutations are $4 \mathrm{bp}$ deletions in exon 7 and this seems to be an area of increased susceptibility. Mutations in exons 7-10 comprise $35-50 \%$ of all mutations (5).

Gs $\alpha$ is ubiquitously expressed and its deficiency results in resistance to PTH as well as to other hormones that signal through $G$ protein coupled receptors such as TSH and gonadotropins $(6,7)$. Interestingly, although vasopressin and adrenocorticotropic hormone (ACTH) also signal via $\mathrm{G}$ protein coupled receptors, resistance to their actions has not been observed in patients with PHP1a. (7). The haploinsufficiency of the GNAS1 gene is tissue specific and in most tissues transcription occurs equally from both alleles. However, in a subset of tissues such as the proximal renal tubules, anterior pituitary, thyroid gland and ovary, expression is monoallelic and is restricted to the maternal allele. This may help elucidate the selective resistance to hormones observed in patients with $\operatorname{PHP}(3,8)$.

In our case, we present two individuals (the proband and his mother) with identical GNAS1 mutations who display the characteristic features of $\mathrm{AHO}$, however differ in their resistance to multiple hormones. This finding can be explained by genomic imprinting of Gs $\alpha$ in which maternal transmission leads to offspring with PHP1a whereas paternal transmission leads to offspring with PPHP, as was the case in the patient's mother. Tissue specific imprinting in addition to "parent of origin" imprinting explains why Gs $\alpha$ expression is equally reduced in PHP1a and PPHP yet only maternal transmission results in proximal renal tubule resistance to PTH (9).

Congenital hypothyroidism has been reported as the presenting manifestation of $\operatorname{PHP}(6,10,11)$. TSH levels are typically elevated at birth but may then normalize for a period 
of months before once again becoming elevated. The resistance to $\mathrm{TSH}$ is generally mild, and this may be explained by partial imprinting in the thyroid with incomplete silencing of the paternal allele (8). Goiter is typically absent given that the defect lies in TSH signaling (12) and antithyroid antibodies are also absent (9). A very small thyroid nodule was present since birth in our patient. Although unclear, it may be possible that this thyroid nodule could be linked to TSH resistance.

The terms calcinosis cutis and osteoma cutis are often used interchangeably in the literature when describing the subcutaneous manifestation of PHP1a. Calcinosis cutis differs from osteoma cutis in that it describes a group of disorders in which insoluble compounds of calcium are deposited within the skin rather than true bone (as is the case in osteoma cutis). Ectopic bone formation (osteoma cutis and progressive osseous heteroplasia) has been observed in patients with $\mathrm{AHO}$. Progressive osseous heteroplasia $(\mathrm{POH})$ is a form of heterotopic ossification $(\mathrm{HO})$ that progresses from superficial tissues into the deeper connective tissues including muscle and fascia but is not associated with $\mathrm{AHO}$ or hormone resistance. It is caused by paternal inheritance of the GNAS1 mutation (13). These syndromes are all associated with heterozygous mutations in GNAS1 which leads to decreased expression or function of Gs $\alpha$. This decreased Gs $\alpha$ activity has been directly linked to osteogenic differentiation in human mesenchymal cells and this finding provides a potential explanation for the ectopic bone formation in these syndromes (14). This results in a spectrum of extra-skeletal ossification disorders with $\mathrm{POH}$ and progressive heterotopic ossification syndromes lying at the far end of the phenotypic spectrum. Although PHP1a is typically associated with a non progressive form of heterotopic ossification, PHP1a with a progressive form of $\mathrm{HO}$ has been described (15). There is no specific genotype-phenotype correlation that distinguishes the non progressive forms of heterotopic ossification from the progressive forms (13).

The pathogenesis of calcinosis cutis is not completely understood and it may develop in response to local and/or systemic factors such as collagen vascular diseases, cutaneous neoplasms, infections and trauma (16). Given that calcinosis cutis is not found in patients with primary hypoparathyroidism, it is less likely that hypocalcemia and hyperphosphatemia are contributing to this clinical picture (17). Moreover, in case reports describing calcinosis cutis in patients with PHP1a, the calcium levels were normal or only marginally above reference values $(17,18)$. Intracranial calcifications and cataracts have also been observed in patients with hypoparathyroidism and PHP. Unlike calcinosis cutis, these calcifications do appear to be caused by the hypocalcemia and hyperphosphatemia (1). It is unclear if calcinosis cutis lies at the milder end of the spectrum of heterotopic ossification. Besides osteoma cutis, other features of $\mathrm{AHO}$ may include obesity, psychomotor retardation and tall stature with advanced bone age. Studies have implicated haploinsufficiency of Gs $\alpha$ as a cause of accelerated differentiation of chondrocytes and osteoblasts and premature epiphyseal fusion leading to an advanced bone age (8).

The mainstay of treatment for PHP involves the administration of oral calcium and $1 \alpha$-hydroxylated vitamin D metabolites, such as calcitriol. This therapy should be initiated in every patient with a diagnosis of PHP with the goal of maintaining serum total and ionized calcium levels within the reference range to avoid hypercalciuria and to maintain PTH levels in the normal range. PTH indirectly activates osteoclasts which are involved in bone resorption and accelerates bone remodeling. In patients with PHP there is variable responsiveness of the skeleton to PTH despite clinical evidence of impaired hormone responsiveness in other tissues including the kidney (19). In the absence of skeletal osteoclast resistance to $\mathrm{PTH}$, hyperparathyroid bone disease such as osteopenia or osteitis fibrosa may develop. Therefore, it is important to maintain $\mathrm{PTH}$ in the normal/upper normal range even in the asymptomatic normocalcemic patient $(20,21)$. Skeletal responsiveness to PTH may help explain the periods of spontaneous normocalcemia observed in some patients (19). The finding of elevated PTH levels in the context of normocalcemia suggests that hypocalcemia may not be the only factor leading to hyperparathyroidism in PHP. Factors contributing to the hyperparathyroidism in PHP may include frequent small unrecognized declines in the serum calcium concentration in addition to a reduction in 1,25-dihydroxyvitamin D. Other suggested explanations include secretion of an abnormal PTH, or abnormal metabolism of PTH (22).

In summary, we report a case of PHP 1A presenting with congenital hypothyroidism with a small thyroid nodule and osteoma cutis. The Gs- $\alpha$ mutation can present with variable effects on phenotype and clinical clues provide valuable information.

\section{References}

1. Wilson L, Hall C. Albright's Hereditary Osteodystrophy and Pseudohypoparathyroidism. Semin MusculoskeletRadiol 2002;6:273-284. [Abstract]

2. Albright F, Burnett C, and Smith P. Pseudohypoparathyroidism: An example of 'Seabright-Bantam syndrome'. Endocrinology 1942;30:922-932.

3. Bastepe and H Juppner. GNAS locus and Pseudohypoparathyroidism. Horm Res 2005; 63:65-74. [Abstract] / [PDF]

4. Bastepe and H. Juppner. Pseudohypoparathyroidism and mechanisms of resistance toward multiple hormones: molecular evidence to clinical presentation. J Clin Endocrinol Metab 2003;88:4055-4058. [Full Text] / [PDF]

5. Ahrens W, Hiort O, Steadt P, Kirschner T, Marschke C, Kruse K. Analysis of the GNAS1 gene in Albright's Hereditary Osteodystrophy. J Clin Endocrinol Metab 2001; 86:46304634. [Abstract] / [Full Text] / [PDF] 
6. Levine MA, Downs RW, Moses AM, Breslau NA, Marx SJ, Lasker RD, Rizzoli RE, Aurbacj GD, Speigal AM. Resistance to multiple hormones in patients with pseudohypoparathyroidism: association with deficient activity of guanine nucleotide regulatory protein. Am J Med 1983;74:545-556. [Abstract] / [Full Text] / [PDF]

7. Spiegel A. G protein defects in signal transduction. Horm Res 2000;53:17-22. [Abstract] / [Full Text] / [PDF]

8. Plagge A, Kelsey Gavin, Germain-Lee E. Physiological functions of the imprinted GNAS locus and its protein variants G.S and XL.S in human and mouse. Journal of Endocrinology 2008;196:193-214. [Abstract] / [Full Text] / [PDF]

9. Weinstein L, Yu S, Warner D, and Liu, J. Endocrine manifestations of stimulatory G-protein alpha-subunit mutations and the role of genomic imprinting. Endocr Rev 2001; 22:675-705. [Abstract] / [Full Text] / [PDF]

10. Weisman Y, Golander A, Spirer Z \& Farfel Z. Pseudohypoparathyroidism type 1a presenting as congenital hypothyroidism. J Pediatr1985;107:413-415. [Full Text]

11. Pinsker J, Rogers W, Mclean S, Schaeffer F, Fenton C. Pseudohypoparathyroidism Type 1a with congenital Hypothyroidism. JPEM 2006;19:1049-1052. [Abstract]

12. Shatlin S, Davidovits M, Lazar L, Weintrob N. Clinical Heterogeneity of pseudohypoparathyroidism: from hyper-to hypocalcemia. Horm Res 2008;70:137-144. [Abstract] / [Full Text] / [PDF]

13. Adegbite NS, Xu M, Kaplan FS, Shore EM, Pignolo RJ. Diagnostic and mutational spectrum of progressive osseous heteroplasia $(\mathrm{POH})$ and other forms of GNAS-based heterotopic ossification. Am J Med Genet 2008; Part A 146A:1788-1796. [Abstract] / [Full Text]

14. Lietman S, Ding, C, Cooke, D, Levine, M. Reduction in Gs[alpha] Induces Osteogenic Differentiation in Human Mesenchymal Stem Cells. Clin Orthop Relat Res 2005;434: 231-238. [Abstract]
15. Gelfand I, Hub R, Shore E, Kaplan F, DiMeglio L. Progressive osseous heteroplasia-like heterotopic ossification in a male infant with pseudohypoparathyroidism type 1a: a case report. Bone 2007;40:1425-1428. [Abstract] / [Full Text] / [PDF]

16. Walsh JH, Fairley JA. Calcifying disorders of the skin. J Am Acad Dermatol 1995;33:693-706. [Abstract] / [Full Text]

17. Riepe F, Ahrens W, Krone N, Fölster-Holst R, Brasch J, Sippell W, Hiort $O$ and Partsch C Early manifestation of calcinosis cutis in pseudohypoparathyroidism type la associated with a novel mutation in the GNAS gene. Eur $J$ of Endocrinol 2005;152:515-519. [Abstract] / [Full Text] / [PDF]

18. Poomthavorn P, Zacharin M. Early manifestation of obesity and calcinosis cutis in infantile pseudohypoparathyroidism. J Paediatr Child Health 2006;42(12):821-823. [Abstract] / [Full Text] / [PDF]

19. Ish-Shalom S, Rao LG, Levine MA et al. Normal parathyroid hormone responsiveness of bone-derived cells from a patient with pseudohypoparathyroidism. J Bone Miner Res 1996;11:8-14. [Abstract]

20. Burnstein MI, Kottamasu SR, Pettifor JM, Sochett E, Ellis $\mathrm{BI}$, Frame B. Metabolic bone disease in pseudohypoparathyroidism: radiologic features. Radiology 1985;155:351-356. [Abstract] / [PDF]

21. Tamada $Y$, Kanda S, Suzuki H, Tajima $T$, Nishiyama $T$. A Pseudohypoparathyroidism Type la Patient with Normocalcemia. Endocr J 2008; 55:169-173. [Abstract] / [PDF]

22. Werder EA, Fischer JA, Illig R et al. Pseudohypoparathyroidism and idiopathic hypoparathyroidism: relationship between serum calcium and parathyroid hormone levels and urinary cyclic adenosine-3',5'-monophosphate response to parathyroid extract. J Clin Endocrinol Metab 1978; 46: 872-879. [Abstract] / [Full Text] / [PDF] 